\title{
MM-SQAP: Method for Modeling Software Quality Assurance Process
}

\author{
Denise Lazzeri Gastaldo Bombonatti ${ }^{1}$, Flávio Lenhari ${ }^{2}$ \\ ${ }^{1}$ QFocus Serviços de Tecnologia da Informação Ltda - Brasil \\ ${ }^{2}$ Wipro IT Business - Brasil \\ denise@qfocus.com.br, flenharilgmail.com
}

\begin{abstract}
This experience report describes MM-SQAP (Method for Modeling Software Quality Assurance Process). This method was defined and applied in a financial company in order to establish its software quality assurance process. The results obtained with this application demonstrated its feasibility. The application of MM-SQAP in other areas, in different domains, will make it more flexible than its original version.
\end{abstract}

Resumo. Este relato de experiência descreve o MM-SQAP (Método para Modelagem de Processo de Garantia de Qualidade de Software). Este método foi definido e aplicado em uma empresa da área financeira para estabelecer seu processo de garantia da qualidade de software. Os resultados obtidos com sua aplicação mostraram sua viabilidade. A sua aplicação do MM-SQAP em outras áreas, em diferentes domínios, fará com que seja possível torná-lo mais flexível que sua versão inicial.

\section{Introduction}

Quality is a broad and complex term, so it is essential to establish quality concept. In manufacturing, for example, quality defines the product that should meet your specification [Crosby apud Sommerville 2007]. Quality can also be defined as a measurable characteristic or attribute that can be compared with known standards, such as length, color, electrical properties and flexibility [Pressman 2011]. Quality can also have a popular and professional meaning. From a popular view, quality can be vague, intangible or even a reference to luxury, class and sophistication. From the professional point of view, quality is precise, measured and must meet the requirements specified by the user [Kan 2002]. In this paper, we applied the concept from a professional point of view, that is, quality must be precise, measured and meet the specified requirements.

Software quality, in turn, has evolved significantly in recent years. One reason for this evolution is the adoption by enterprises, technological solutions related to software development and software quality assurance [Sommerville 2011]. Software quality assurance has become essential in software development since it is an activity applied throughout the development process [Pressman 2011].

Due to the software quality assurance process, indicators have major importance. Indicators allow having a clear idea about the effectiveness of processes, including 
quality processes and, therefore, of the performance of software projects [Pressman 2011]. Indicators, performance measures, process development and quality assurance are also part of fundamental aspects herein.

The aim is to present MM-SQAP definition and application. MM-SQAP is a modeling method that means to present the necessary activities to define and implement a quality assurance software process.

Process definition was based on CMMI product and process quality assurance (PPQA) process area [Chrissis, Konrad and Shrum 2007], ISO 9001:2008 [ISO 2008] from the perspective of continuous process improvement and IT governance principles [IT Governance Institute 2007], since the quality of the software should be aligned with the organization's IT goals.

According to CMMI [Chrissis, Konrad and Shrum 2007], the PPQA process area must objectively evaluate process \& work products and provide objective insight to management. Process and work products objective evaluations are usually performed by a set of defined criteria included in a verification list. Verification lists include criteria to evaluate adherence to applicable process descriptions, standards and procedures. Noncompliance issues are identified, tracked and communicated when objective insight is provided to management. The objective is to ensure non-compliance proper resolution. Issues can be communicated to staff and organization by a set of indicators and reports.

This work is structured in five chapters. Chapter 1 presents the introduction; chapter 2 presents MM-SQAP; chapter 3 presents the application in a financial company; chapter 4 presents the results and chapter 5 presents the conclusion.

\section{MM-SQAP Presentation}

MM-SQAP is a method for modeling the software quality assurance process. The result of MM-SQAP is a software quality assurance process, activities, artefacts and a set of indicators for assessing their performance. MM-SQAP differential is the definition of a technological architecture that supports the automation of software quality assurance process and metrics collection.

MMP-SQA consists of two distinct perspectives: phases and product groups. Phases are composed by survey, definition, specification, construction, simulation, proof of concept, refinement and deployment. Product groups are composed by policies and process, indicator, architecture, support system, prototype and pilot. MM-SQAP is presented in figure 1. 


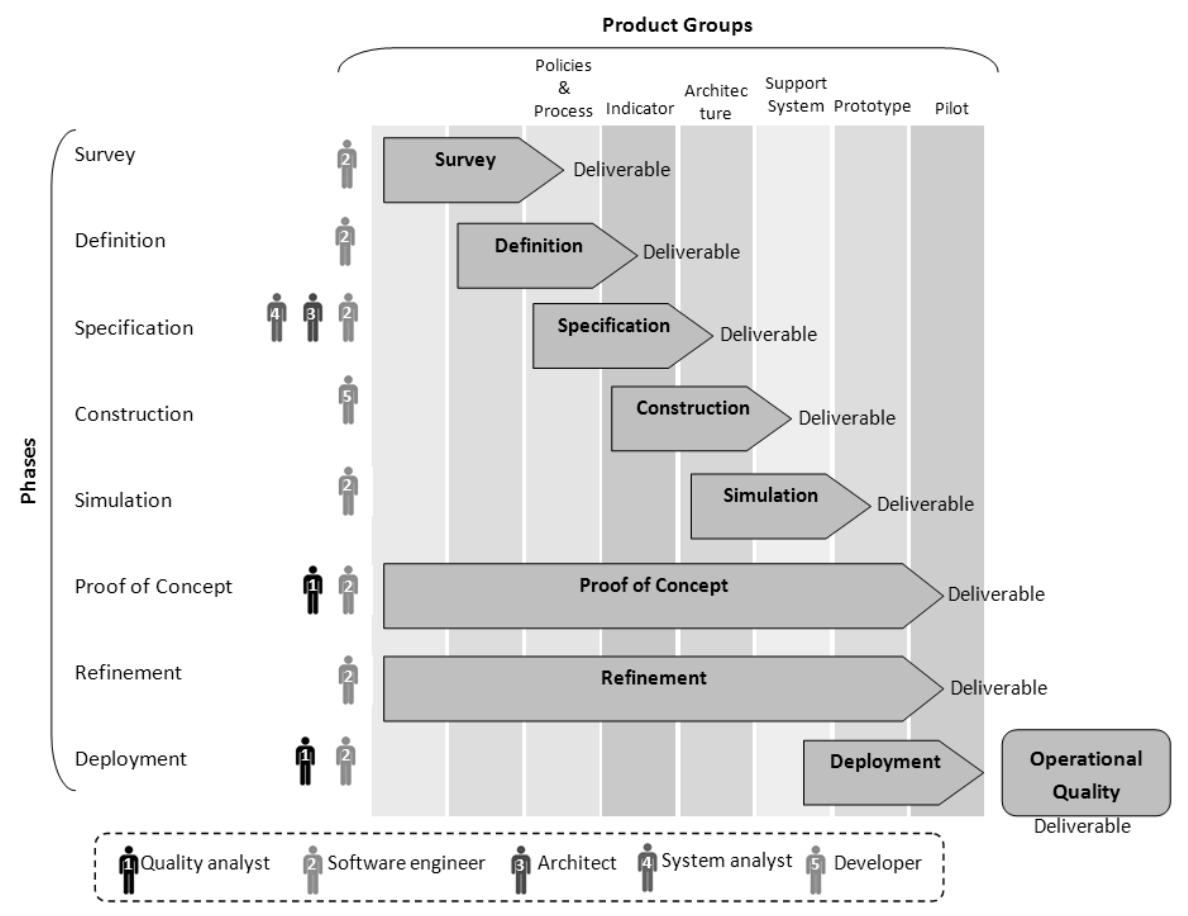

Figure 1. MM-SQAP phases and product groups.

Phases, in figure 1, present a cycle of activities performed in a sequential timeline. Some overlapping can be observed between phases. This can happen because deliverables can start to be produced before the current phase has been completed; therefore, it can be characterized as partial deliveries, until they become final, at the end of each phase.

Product groups perspective present a set of products produced for each phase along timeline. Timeline is the link between phase and products perspectives. Intersection between perspectives produces MM-SQAP deliverables. Each deliverable is composed of work products.

Each phase requires different profiles, according to MM-SQAP. Survey, definition, simulation, proof of concept, refinement and deployment phases require a software engineer profile. A system analyst profile is required by the specification phase. The specification phase also requires an architect profile. A developer is required during the construction phase. The proof of concept phase requires a quality analyst profile.

The survey phase defines quality policies, guidelines, roles $\&$ responsibilities, a survey on the current software development process and an overview of software quality assurance process definitions. These artefacts are submitted to organization approval, and, once approved, the software quality assurance process can be established.

The definition phase identifies software quality assurance sub processes with related activities and procedures. The primary set of metrics must also be identified. The definition phase also establishes acceptance criteria for work products and processes. During this phase, the metrics data model is defined in order to compose the base for the indicators panel. 
The specification phase selects the technological architecture in order to meet process automation needs. At this stage, the technological platform is defined and detailed. In addition, technical specifications are developed including integrations and automation needs.

The construction phase develops verification lists of the software quality assurance process. In this phase, indicator prototypes are defined. Automation and integration between systems are implemented.

The simulation phase tests prototypes for system and indicator panel. Architecture, integration and automations are tested. Indicator panel are simulated based on metrics definitions.

The proof of concept phase identifies pilot projects in order to apply tested prototypes. During this phase, data related to pilot execution must be collected in order to improve the process.

The refinement phase collects all the improvement opportunities recorded during the proof of concept phase and embodies them into process definitions. At this phase, deliverables from previous phases can be reviewed and refined.

The deployment phase starts the communication to all the software quality assurance process stakeholders. Training sections are performed in order to disseminate knowledge.

Table 1 shows the breakdown of deliveries and activities performed by intersection between phases and product groups.

Table 1. MM-SQAP activities and deliverables.

\begin{tabular}{|c|c|c|c|}
\hline Phase & Product Groups & Activities & Deliverables \\
\hline Survey & Policics \& Proccss & $\begin{array}{l}\text { Idcntify policics and quality corporativc } \\
\text { directions } \\
\text { Define roles and responsibilities } \\
\text { Evaluate current software development process } \\
\text { Define quality assurance process }\end{array}$ & $\begin{array}{l}\text { Policics and corporativc quality dircctions } \\
\text { Roles and responsibilities } \\
\text { Software development process survey report } \\
\text { Quality assurance process overview definition }\end{array}$ \\
\hline Definition & Indicator & $\begin{array}{l}\text { Define process metrics } \\
\text { Define sub processes } \\
\text { Detail activities } \\
\text { Establish products and process acceptance } \\
\text { criteria } \\
\text { Define indicators panel } \\
\text { Establish indicators acceptable limits } \\
\text { Elaborate metrics data model } \\
\text { Establish continuous improvement plan }\end{array}$ & $\begin{array}{l}\text { Process metrics } \\
\text { Sub processes } \\
\text { Activities } \\
\text { Product acceptance criteria } \\
\text { Process acceptance criteria } \\
\text { Indicators panel } \\
\text { Indicators limits } \\
\text { Data model } \\
\text { Continuous improvement plan }\end{array}$ \\
\hline Specification & Architecture & $\begin{array}{l}\text { Establish technological platform } \\
\text { Define automations and integrations } \\
\text { Specify technical solutions }\end{array}$ & $\begin{array}{l}\text { Technological platform specification } \\
\text { Automations and integrations specification } \\
\text { Technical solution specification }\end{array}$ \\
\hline Construction & Support System & $\begin{array}{l}\text { Develop process artifacts } \\
\text { Develop process verification lists } \\
\text { Develop product verification lists } \\
\text { Build indicators prototype } \\
\text { Build quality assurance system } \\
\text { Build automations and integrations }\end{array}$ & $\begin{array}{l}\text { Process artifacts } \\
\text { Process verification lists } \\
\text { Product verification lists } \\
\text { Indicators panel } \\
\text { Quality assurance system prototype } \\
\text { Automations and integrations } \\
\end{array}$ \\
\hline Simulation & Prototype & $\begin{array}{l}\text { Test and collect indicators } \\
\text { Test work products } \\
\text { Test quality assurance system } \\
\text { Test automations and integrations }\end{array}$ & $\begin{array}{l}\text { Indicators test report } \\
\text { Work products test report } \\
\text { Quality assurance system test report } \\
\text { Automations and integrations test report }\end{array}$ \\
\hline $\begin{array}{l}\text { Proof of } \\
\text { Concept }\end{array}$ & Pilot & $\begin{array}{l}\text { Select pilot projects } \\
\text { Define pilot execution criteria } \\
\text { Perform quality assurance process } \\
\text { Produce indicators }\end{array}$ & $\begin{array}{l}\text { Pilot plan } \\
\text { Pilot execution results }\end{array}$ \\
\hline Refinement & Pilot & Analyze pilot results & Improvements opportunities \\
\hline Deployment & Operational Quality & $\begin{array}{l}\text { Train development teams } \\
\text { Train quality assurance team } \\
\text { Perform final process }\end{array}$ & $\begin{array}{l}\text { Training to development teams } \\
\text { Training to quality assurance team } \\
\text { Operational quality }\end{array}$ \\
\hline
\end{tabular}




\section{MM-SQAP Application Context}

Before applying the PPQA process area in a financial company, process and work products reviews were performed in an ad-hoc manner. The quality team was composed of two quality specialists, who supported the whole organization. Some areas expressed their interest in improving the quality of their processes and work products with the help of the quality team. The previous process was based on quality team skills and it was completely dependent on people and on the quality team perspective to diagnose issues and non-conformances.

In the previous organization structure, the quality focus was to define processes, tools and indicators. Some quality analysts were hired to help with the process and product objective evaluations. These evaluations were not based on a defined set of criteria and it was not aligned with the quality area strategy. Indicators were not properly collected.

Due to this scenario, the PPQA process improvement initiative aimed to redefine a framework for evaluating processes and work products according to the software methodology and review tools and team structure in order to support overall organization.

The improvement initiative took place over three months and it was performed by eleven members with the following roles and responsibilities:

- Quality specialists: two members responsible for improvement initiative settings, deadlines, scope, risk management and good practices.

- Outsourcing partner: two members responsible for quality assurance process definitions, process and work products verification definitions. Two members responsible for architecture specification and system construction.

- Quality analysts: five members responsible for carrying out the process and the work product reviews. They were considered key project stakeholders and end users.

This group was responsible for all aspects and decisions from the policy draft for high quality management to detailed definitions of procedures.

The project selected for the pilot project was an expansion of the bank treasury. This project was the source of many new developments and affected a large number of teams. It was a good opportunity to apply the improvements.

\section{MM-SQAP Results Analysis}

Results of MM-SQAP application were analyzed per phase. The survey phase identified that it was essential to obtain the top management involvement in order to adopt policies and guidelines. These directions were important to established process metrics and indicators. 
The definition phase appointed that the most important point was to involve the whole team to understand the reason and rationale for each metric and indicator. It is mandatory that every team finds the value in getting the indicators. During definition phase an indicators panel was generated. Examples of these indicators were:

- Percentage of software quality assurance evaluations performed according to schedule;

- Compliance percentage of work products and software development process;

- Effort spent during software quality assurance evaluations per period;

- Percentage of non-conformances and improvement actions by state.

The specification phase presented some issues related to lack of support and engagement of architects to develop a proper solution. It happened because the architect team was not convinced of the project importance and value. Meetings were held to solve these problems in order to demonstrate the project benefits to the organization.

The simulation phase demonstrated some problems related to poor planning of the testing strategy. Many errors were found during tests. Test cycles were performed to correct all pending points.

Proof of concept was the most difficult phase. The improvement initiative team realized that quality analyst profiles were not adequate to perform such process and products evaluations. The team knowledge was not enough to perform the activities. Definitions made during the project were not accepted by the quality analyst team that demonstrated a lot of resistance. Conflicts were managed by the human resources team.

The refinement phase released a new software quality assurance process, reviewed according to the pilot execution. Figure 2 presents the pilot results related to work products evaluations performed by the quality analysts.

The result presented in figure 2 shows some discrepancies between work product evaluations in MAN (management artefact), TEC (technical artefact) and TES (test artefact).

In some cases, quality analysts performed work product evaluation in different spans of time. Some points were discovered, such as, quality analysts have different levels of knowledge and, in some cases, each quality analyst has specialties in specific work product evaluations. The results analysis demonstrated that knowledge should be consolidated between the team and the quality team leader could allocate specific verifications to specialized resources. Process and work product verification lists contents were evaluated and some reviews were performed to adapt the content in order to clarify the criteria. 


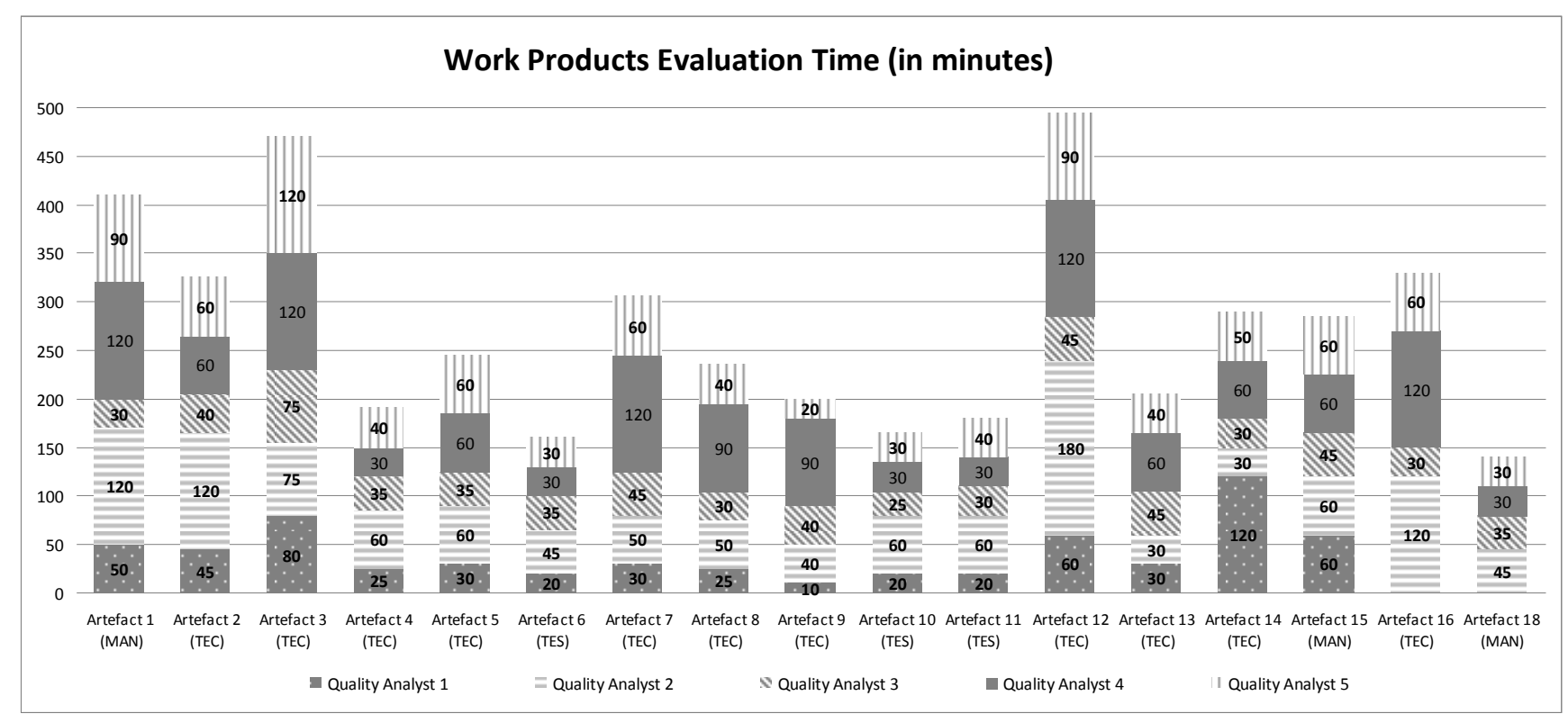

Figure 2. Work products evaluations by quality analysts.

During the pilot, it was also noted that it was necessary to involve all the stakeholders in order to reduce resistance. Resistance can be reduced if all stakeholders have the same level of information.

The deployment phase performed knowledge dissemination through a set of workshops in order to align the entire organization about software quality assurance process definitions. Workshops took into consideration the culture of that financial company.

This improvement initiative showed that it was important to properly manage the involvement of the quality analyst team and the architecture team. In the first case, the quality team demonstrated much resistance to change the current practices. In the second case, the architecture team demonstrated lack of commitment with this initiative. In both cases, the project team was responsible for dealing with conflicts and for solving the issues with proper support.

The final project benefits with this project execution were: (1) improvement of process and work products evaluations; (2) management based on indicators which avoided subjectivity to take actions related to quality assurance process; (3) dissemination of quality culture; (4) resistance decrease and risk mitigation; (5) value generation from the project leader perspective in relation to quality management; (6) process and work products automation; (7) review of the quality team organization with roles and responsibilities definition. 


\section{Conclusion}

This experience report described MM-SQAP. This method was defined and applied in a financial company in order to establish its software quality assurance process.

With MMP-SQA, it was possible to obtain a software quality assurance process definition and a set of indicators related to this process. The MMP-SQA application also allowed the implementation of outsourcing activities for process and work product evaluations.

The software quality assurance process resulting from the MMP-SQA application was refined and published to the organization. Quality stakeholders were trained during the process deployment.

The pilot results were recorded and opportunities for improvement were presented. It was collected from a large set of activities related to process and work product evaluation. Reviews were focused primarily on details of process activities and procedures, verification lists and automation \& integration corrections. The pilot did not identify the need for adjustments in policy, guidelines, processes and sub processes.

During the pilot it was perceived that the quality analyst's profiles must be improved. Most of the problems faced during the pilot with quality analysts referred to how to conduct proper reviews to process and work products.

MM-SQAP was feasible to define the software quality assurance process in a financial company. It also demonstrated that it is important to control the process based on indicators. MM-SQAP can also be applied in different areas and fields due to its broad definition. These applications will make MM-SQAP more flexible than its original version.

MMP-SQAP should be continuously evolved, so that it can embody quality indicators correlations, such as cost, time and delivery, as well as allowing the correlation between other indicators needed for the business.

\section{References}

Chrissis, M. B, Konrad, M. and Shrum, S. (2007) CMMI: Guidelines for Process Integration and Product Improvement, Addison Wesley, $2^{\text {nd }}$ edition.

Crosby, P. (1979) apud Sommerville, I. (2007), Quality is free, McGrawHill.

ISO (International Organization for Standardization) (2008), Quality Management Systems - Requirements.

IT Governance Institute (2007), COBIT 4.1, IT Governance Institute.

Kan, S. H. (2002) Metrics and Models in Software Quality Engineering, Addison Wesley, $2^{\text {nd }}$ edition.

Pressman, R. S. (2011) Software Engineering, McGrawHill, $7^{\text {th }}$ edition.

Sommerville, I. (2011) Software Engineering, Addison Wesley, $9^{\text {th }}$ edition. 